\title{
Self-esteem, job insecurity, and psychological distress among Chinese nurses
}

\author{
Yun Liu', Chunyan Yang ${ }^{1}$ and Guiyuan Zou ${ }^{2^{*}}$
}

\begin{abstract}
Background: Many studies investigate the variables relating to psychological distress among nurses, but little is known about the underlying mechanism(s) among job insecurity, self-esteem, and psychological distress.

Aims: This cross-sectional study examines the prevalence of psychological distress among nurses and the relationships among job insecurity, self-esteem, and psychological distress; it also explores how self-esteem might mediate between job insecurity and psychological distress.

Methods: Questionnaires that assess job insecurity, self-esteem, and psychological distress were collected from 462 nurses in a tertiary hospital in Shandong Province, China.

Results: Our results show an $83.3 \%$ prevalence rate for psychological distress among nurses. Regression analysis results show that job insecurity positively correlates with psychological distress, explaining $17.5 \%$ of the variance in psychological distress. Mediation analysis results show that self-esteem partially mediates the effect of the two dimensions of job insecurity on psychological distress.
\end{abstract}

Conclusions: Psychological distress is prevalent among Chinese nurses. Nursing administrators should take effective measures to improve self-esteem and reduce the negative impacts of job insecurity on nurses, including psychological distress.

Keywords: Job insecurity, Self-esteem, Psychological distress, Mediation, Nurse, China

\section{Introduction}

Over the last decade, psychological distress among nurses has been a research focus among researchers in occupational health [1-3]. Several researchers have found not only that psychological distress is a risk predictor of psychosomatic function and quality of life [1, 4]: it also gives rise to poor job performance and high turnover rates, both of which undoubtedly affect nursing professionalism and quality of care [5, 6]. Today, ongoing changes in the healthcare profession-such as

\footnotetext{
* Correspondence: zouguiyuan00@126.com

${ }^{2}$ Shandong Mental Health Center, 49Wenhua East Road, 250012 Jinan, P.R. China

Full list of author information is available at the end of the article
}

fiercer competition among hospitals, changing employment relations, increased workloads, and deficiencies in both technical knowledge and decision-making autonomy-have resulted in organizational and personal challenges $[7,8]$. These challenges-coupled with rapid economic development, general population aging, the growing burden of chronic diseases, unreasonable expectations among administrators and patients, and unsafe working conditions or practice environments-have led to increased psychological distress and caused nurses to feel insecure about their jobs $[9,10]$.

"Job insecurity" is defined as the subjective perception of a potential threat to the continuity of one's current job [11]. "Quantitative job insecurity" refers to an overall 
concern about the continued existence of the job in the future $[12,13]$. "Qualitative job insecurity," on the other hand, refers to perceived threats of impaired quality in the employment relationship, such as a reduction in income, a lack of career opportunities, and the deterioration of working conditions [12]. Job insecurity is a form of job stress that undoubtedly affects professional performance and psychosomatic health [14-16]. In addition, researchers have found a significant relationship between job insecurity and sleep disorders, psychological distress, burnout, job satisfaction, and problems with family relationships $[16,17]$. While a large number of population-based empirical studies have investigated the detrimental effects of job insecurity on work-related attitudes and health and well-being outcomes, studies on the relationship between job insecurity and psychological distress among nurses are limited [18, 19].

Self-esteem has also attracted research attention as a psychosocial determinant of nurse health [20, 21]. Selfesteem is defined as an individual's feelings regarding their personal worth, competence, and suitability [22, 23]. Studies have shown that self-esteem is one of the strongest predictors of life satisfaction, and it negatively correlates with psychological distress (especially in the forms of anxiety, depression, interpersonal problems, and high values in terms of the general severity index of symptom disorders) [24-26]. Thus, self-esteem is important to an individual's psychological development. Self-esteem is a psychological determinant that can help individuals effectively cope with stressful dilemmas [23, 27]. Previous surveys found that self-esteem negatively correlates with perceived stress [22], and that it is worthwhile to consider self-esteem as an intermediary variable $[21,28,29]$. For example, Wang revealed that an individual's self-esteem could mediate the relationship between occupational stress and well-being [27]. Based on these facts, we assert that self-esteem might mediate the effects of job insecurity among nurses, especially psychological distress.

\section{Objectives}

This cross-sectional study looks to achieve the following aims. First, it investigates the prevalence of psychological distress among Chinese nurses; second, it examines the relationships among job insecurity, self-esteem, and psychological distress; finally, it explores the mediation of self-esteem on job insecurity and psychological distress.

\section{Methods}

\section{Study design, setting, and sampling, and ethical} considerations

We undertook our cross-sectional study in a tertiary hospital in Shandong Province, China, from July 2018 to September 2018; we used convenience sampling to survey registered nurses. We calculated the sample size as per the following formula: $\mathrm{N}=(\mu \alpha \mathrm{S} / \delta)^{2}$ (where $\mu_{\alpha}=$ 1.96 , and the $S / \delta$ value $=10$ according to the pilot study); in so doing, considering $20 \%$ nonresponse rates, we found the minimum sample size was 461 . A total of 480 nurses employed at the hospital were invited to participate in the survey, to which 462 of them responded (response rate: $96.25 \%$ ). The inclusion criteria for the participants were as follows: (a) held a nursing practice license in the People's Republic of China, and (b) were directly involved in a nursing unit (i.e., internal medicine department, surgical department, intensive care unit, emergency department, or gynecology department).

Our study design and procedures were approved by the ethics committee of Shandong Mental Health Center (2018R23). These procedures were conducted in accordance with the ethical standards of the 1964 Helsinki Declaration. All participants were informed of the purposes and procedures of the study and provided written informed consent.

\section{Data collection procedures}

Prior to formal execution, we telephoned each head nurse and explained the purpose of our study, and invited them to promote our research among the nurses. Data collection was conducted separately in each participating hospital ward.

Participants were informed orally and in writing of the study's purpose, along with information on their rights as participants and the anonymity of this research project; we invited them to participate in our survey (i.e., a selfadministered hard-copy questionnaire), which they were instructed to complete in a staff room or health education room following their daily work. The questionnaire required approximately 10-15 min of completion time. Ultimately, 462 nurses returned the completed questionnaires (response rate: $96.25 \%$ ). The most frequently cited reason for refusal was a lack of interest in the survey.

\section{Participants' sociodemographic characteristics}

The sociodemographic characteristics of the participants included age, gender, educational level, marital status, economic status, years of work experience, and job type.

\section{Rosenberg self-esteem scale}

The Rosenberg self-esteem scale (RSES), a measure of individual self-esteem, comprises 10 items such as "All in all, I am inclined to feel that I am a failure." [30]. The respondents rated each item according to the extent to which they agreed with the statement therein, on a fourpoint Likert scale whose values ranged from 1 (do not agree at all) to 4 (agree completely). Answers were summed to obtain a total score ranging from 10 to 40 , 
with a higher score indicating a higher level of selfesteem. Factor analysis has shown the Chinese version of the RSES to be a valid single structure, and its alpha reliability for Chinese nurse sample ranges from 0.83 to 0.85 [31, 32]. In this survey, the Cronbach's $\alpha$ of the RSES is 0.79 .

\section{Kessler-10 rating scale}

We used the Kessler-10 (K10) rating scale developed by Kessler and Mroczek to evaluate the level of mental health among the nurses [33]. This scale consists of 10 items; we obtained a response to each item via a fivepoint Likert scale with values ranging from 1 (not at all) to 5 (extremely). The total score for each participant ranged from 10 to 50, with a higher total score indicating a higher level of psychological distress. A total score $\geq 16$ indicates psychological distress. Many studies support the psychometric properties of the $\mathrm{K} 10$ as a measure of mental health among clinical and nonclinical samples [34, 35]. Moreover, the $\mathrm{K} 10$ has also being found to be reliable and generate valid results among Chinese nurses [36], and in the current study its Cronbach's $\alpha$ is 0.92 .

\section{Job insecurity scale}

We evaluated job insecurity using a seven-item scale developed by Hellgren [12]. The scale consists of two dimensions-one containing three items, and the other four-and it was designed to evaluate quantitative and qualitative insecurity. Participants were required to rate each item on a five-point Likert scale ranging from 1 (strongly disagree) to 5 (strongly agree). A combination of higher quantitative and qualitative insecurity indicated greater job insecurity. The scale has been proven valid $(\mathrm{x} 2 / \mathrm{df}=2.283, \mathrm{CFI}=0.979, \mathrm{NFI}=0.974, \mathrm{RMSEA}=0.076)$ and reliable in measuring job insecurity experienced by clinical nurses [37]. (In the current study, the Cronbach's $\alpha$ is $0.730,0.949$, and 0.903 for the overall job insecurity scale and the subscales.) In the current study, the Cronbach's $\alpha$ for the quantitative and qualitative insecurity is 0.76 and 0.87 , respectively.

\section{Data analysis}

We used the Statistical Package for the Social Sciences (SPSS) software (v22) (IBM Corp., Armonk, NY, USA) in all analyses. We calculated descriptive statistics for psychological distress, job insecurity, self-esteem, and sociodemographic information. We used an analysis of variance or $t$-test to evaluate differences among the participants in terms of psychological distress, and Pearson's $\mathrm{r}$ was calculated to examine correlations among psychological distress, self-esteem, and job insecurity among nurses in China. We also undertook hierarchical regression analysis to explore the mediating effects of self- esteem between job insecurity and psychological distress, according to Baron and Kenny's method [38], and generated a standardized estimate $(\beta), F, R^{2}$, and $R^{2}$-changes $\left(\Delta R^{2}\right)$ for each step. Finally, we applied a nonparametric resampling method (2000 iterations) by running the PROCESS plugin in the SPSS Macro, as proposed by Preacher and Hayes, to examine the statistical significance of the mediating effect [39]. Before performing the regression analyses, we standardized all continuous variables to prevent multicollinearity. In all analyses, we considered any $p$ value $<0.05$ statistically significant.

\section{Results}

Sociodemographic information and distribution of psychological distress in categorical items

As Table 1 shows, the sample comprises 428 (92.6\%) women and $34(7.4 \%)$ men. The mean age of the participants was $31.19 \pm 6.36$ years, and their average years of work experience was $8.65 \pm 7.12$ months. Regarding duration of employment, $33.3 \%$ had worked as nurses for 6-10 years, and $24.9 \%$ for more than 10 years. In terms of education, $339(73.4 \%)$ of the nurses had earned a bachelor's degree or higher; additionally, $71.9 \%$ were married. Regarding job type, $40.5 \%$ were permanent nurses. We observed no significant differences between psychological distress and sociodemographic information, save for years of work experience and job type.

\section{Scores and correlations among self-esteem, job insecurity, and psychological distress}

Table 2 shows descriptive results with respect to selfesteem, psychological distress, quantitative insecurity, and qualitative insecurity, the scores for which are $28.11 \pm 3.24,23.72 \pm 7.22,7.78 \pm 2.50$, and $6.81 \pm 3.01$, respectively. A total of 387 nurses reported high levels of psychological distress, with $83.8 \%$ of sample scores being $\geq 16$. Table 2 also presents the Pearson's correlation results. Self-esteem negatively correlates with each of quantitative insecurity $(r=-0.278, p<0.01)$, qualitative insecurity $(r=-0.251, p<0.01)$, and psychological distress $(r=-0.374, p<0.01)$. Psychological distress, on the other hand, positively correlates with quantitative insecurity $(r=-0.339, p<0.01)$ and qualitative insecurity $(r=-0.282, p<0.01)$.

\section{Results of hierarchical linear regression analysis}

Our hierarchical linear regression analysis results (Table 3) show that the control variable (i.e., years of work experience) does not significantly correlate with psychological distress in step $1\left(R^{2}=0.001\right)$. Quantitative insecurity $(\beta=0.306, p<0.001)$ and qualitative insecurity $(\beta=0.236, p<0.001)$ are significantly positive predictors 
Table. 1 Sociodemographic information and distribution of psychological distress in categorical items $(N=462)$

\begin{tabular}{|c|c|c|c|c|}
\hline Variable & n (\%) & $\begin{array}{l}\text { Psychological Distress } \\
\text { (Mean } \pm \text { SD) }\end{array}$ & $t / F$ & $\mathbf{P}$ \\
\hline Age & & & 2.034 & 0.132 \\
\hline$<30$ years & $266(57.6)$ & $24.03 \pm 7.14$ & & \\
\hline $31 \sim 40$ years & $150(32.5)$ & $23.79 \pm 7.01$ & & \\
\hline$>40$ years & $46(10.0)$ & $21.72 \pm 8.20$ & & \\
\hline Gender & & & 3.835 & 0.051 \\
\hline Female & $428(92.6)$ & $23.57 \pm 7.07$ & & \\
\hline male & $34(7.4)$ & $25.59 \pm 8.87$ & & \\
\hline Years of working & & & 4.217 & 0.006 \\
\hline$<3$ years & $108(23.4)$ & $24.31 \pm 7.19$ & & \\
\hline $3 \sim 5$ years & $85(18.4)$ & $23.08 \pm 7.12$ & & \\
\hline $6 \sim 10$ years & 154(33.3) & $24.95 \pm 7.09$ & & \\
\hline$>10$ years & 115(24.9) & $22.00 \pm 7.22$ & & \\
\hline Education level & & & 1.590 & 0.208 \\
\hline Junior school or under & 123(26.6) & $23.73 \pm 7.59$ & & \\
\hline Bachelor's degree or above & $339(73.4)$ & $23.72 \pm 7.10$ & & \\
\hline Economic conditions & & $P=0.066$ & 2.730 & 0.066 \\
\hline$<3000 ¥$ & 102(22.1) & $25.03 \pm 7.97$ & & \\
\hline $3000 \sim 5000 ¥$ & 233(50.4) & $23.65 \pm 6.73$ & & \\
\hline$>5000 ¥$ & $127(27.5)$ & $22.80 \pm 7.37$ & & \\
\hline Marital status & & & 0.328 & 0.567 \\
\hline Single & $117(25.3)$ & $23.64 \pm 7.29$ & & \\
\hline Married & $345(74.7)$ & $23.97 \pm 7.05$ & & \\
\hline Job type & & & 18.993 & 0.000 \\
\hline Permanent nurse & $177(40.5)$ & $24.96 \pm 8.13$ & & \\
\hline Temporary nurse & $285(59.5)$ & $22.95 \pm 6.94$ & & \\
\hline
\end{tabular}

of psychological distress in step 2, explaining the $17.5 \%$ variance in psychological distress. In the third step, selfesteem $(\beta=-0.256, p<0.001)$ does not predict psychological distress, and accounts for the $5.7 \%$ variance in psychological distress. When we add self-esteem to the regression model, the relationship with each of quantitative insecurity ( $\beta=0.306$ to $\beta=-0.242, p<0.001$ ), qualitative insecurity $(\beta=0.236$ to $\beta=182, p<0.001)$, and psychological distress significantly attenuates. Based on

Table. 2 Mean, Standard Deviations (SD) and Correlation of Variables

\begin{tabular}{lrllll}
\hline Variables & Mean \pm SD & $\mathbf{1}$ & $\mathbf{2}$ & $\mathbf{3}$ & $\mathbf{4}$ \\
\hline 1 Self-esteem & $28.11 \pm 3.24$ & 1 & & & \\
2 Quantitative Insecurity & $7.78 \pm 2.50$ & $-0.278^{* *}$ & 1 & & \\
3 Quality Insecurity & $6.81 \pm 3.01$ & $-0.251^{* *}$ & $0.147^{* *}$ & 1 & \\
4 Psychological Distress & $23.72 \pm 7.22$ & $-0.374^{* *}$ & $0.339^{* *}$ & $0.282^{* *}$ & 1 \\
\hline ** $P<0.01$ & & & &
\end{tabular}

Table. 3 Hierarchical Linear Regression Analysis Results

\begin{tabular}{llll}
\hline Variable & \multicolumn{3}{l}{ Psychological Distress } \\
\cline { 2 - 4 } & Step3 & Step2 & Step3 \\
\hline Block 1 & & & \\
Years of Working & -0.074 & -0.075 & -0.045 \\
Job type & -0.009 & -0.019 & -0.023 \\
Block 2 & & & \\
Quantitative Insecurity & & $0.306^{* * *}$ & $0.242^{* * *}$ \\
Qualitative Insecurity & & $0.236^{* * *}$ & $0.182^{* * *}$ \\
Block 3 & & & \\
Self-esteem & & & $-0.256^{* * *}$ \\
$\boldsymbol{F}$ & 1.269 & $24.386^{* * *}$ & $27.637^{* * *}$ \\
$\boldsymbol{R}^{2}$ & 0.001 & 0.176 & 0.233 \\
$\Delta \boldsymbol{R}^{\mathbf{2}}$ & 0.001 & 0.175 & 0.057 \\
\hline
\end{tabular}


the fourth step of Baron and Kenny's method, we can conclude that self-esteem partially mediates the relationship between the two dimensions of job insecurity and psychological distress.

Our bootstrapping results (Table 4) indicate that the path coefficient of the indirect effect of quantitative insecurity on psychological distress through self-esteem is 0.2432 (95\% confidence interval [CI]: 0.1437, 0.3826). The path coefficient of the direct effect of quantitative insecurity on psychological distress is 0.7368 (95\% CI: $0.4898,0.9837$ ); our bootstrapping results also show that the path coefficient of the indirect effect of quality insecurity through self-esteem is 0.1979 (95\% CI: 0.1085 , $0.3103)$. The path coefficient of the direct effect of qualitative insecurity on psychological distress is 0.4821 (95\% CI: $0.2759,0.6884$ ). Thus, self-esteem is a partial mediator between each of quantitative insecurity and qualitative insecurity and psychological distress.

\section{Discussion}

To the best of our knowledge, the current study is among the first to examine self-esteem as a potential mediator between job insecurity and psychological distress among Chinese nurses. Our main findings are as follows. The prevalence of psychological distress is $83.8 \%$, and the two dimensions of job insecurity positively correlate with psychological distress, whereas selfesteem negatively correlates with psychological distress. The results of mediation analysis show that self-esteem is a partial mediator between the two dimensions of job insecurity and psychological distress.

Additionally, the findings of the current study also enrich those of earlier surveys [14-16] and explain why not everyone that suffers from job insecurity experiences psychological distress. The prevalence of psychological distress reported in this study resembles that reported elsewhere [23]. We found the years of work experience highly relevant to psychological distress, in that the more years of work experience one has, the less psychological distress they are likely to have; this finding is also consistent with that of a previous survey [36]. In addition, we found that job type relates to psychological distress, in line with existing research results [36,37]. We might also assert that temporary nurses are more likely to accept the inherent instability of contractual employment work than permanent nurses, and this acceptance might manifest as lower levels of psychological distress.

Our research revealed that among nurses, job insecurity and two dimensions of job insecurity positively correlate with psychological distress; this finding aligns with that of Kachi [40]. Other studies confirm that job insecurity has serious consequences not only on individuallevel financial capacity, but also on psychosomatic health $[15,17,41]$. According to conservation of resource theory, when nurses feel that their job stability or continuity is threatened, they will invest considerable psychological, physiological, and emotional resources into maintaining and protecting their job, which is naturally vital to them. However, if their efforts go unrewarded, emotional exhaustion will occur. With the deepening of China's healthcare reforms, more and more of China's nurses will find themselves worried about their job stability, job rewards, and future career development, and this could lead to higher levels of psychological distress $[3,7,9]$.

The current study found that self-esteem negatively correlates with psychological distress; this is a finding observed in previous studies [23, 27]. Feng et al. show that nurses with high positive self-image tend to have greater career adaptability resources, and consequently feel more enthusiastic about their job [23]. Nurses with

Table. 4 Self-esteem mediates the relationship between the dimensions of job insecurity and psychological distress

\begin{tabular}{|c|c|c|c|c|c|c|}
\hline $\begin{array}{l}\text { Independent } \\
\text { Variable }\end{array}$ & $\begin{array}{l}\text { Mediating } \\
\text { Variable }\end{array}$ & Predictor & Pathway & Estimate & SE & $\begin{array}{l}95 \% \text { Cl } \\
\text { LL UL }\end{array}$ \\
\hline \multirow[t]{8}{*}{ Psychological distress } & Self-esteem & Self-esteem: Quantitative Insecurity & $a_{1}$ & -0.3604 & 0.0581 & $-0.4746-0.2462$ \\
\hline & & Psychological distress: self-esteem & $b_{1}$ & -0.6749 & 0.0968 & $-0.8652-0.4846$ \\
\hline & & $\begin{array}{l}\text { Indirect effect through self-esteem psychological } \\
\text { distress: Quantitative Insecurity }\end{array}$ & $a_{1} b_{1}$ & 0.2432 & 0.0601 & 0.14370 .3826 \\
\hline & & $\begin{array}{l}\text { Direct effect of Quantitative Insecurity on psychological } \\
\text { distress }\end{array}$ & $c_{1}$ & 0.7368 & 0.1257 & 0.48980 .9837 \\
\hline & & Self-esteem: Quality Insecurity & $a_{2}$ & -0.2706 & 0.0486 & $-0.3663-0.1751$ \\
\hline & & Psychological distress: self-esteem & $b_{2}$ & -0.7201 & 0.0974 & $-0.9116-0.5287$ \\
\hline & & $\begin{array}{l}\text { Indirect effect through self-esteem psychological distress: } \\
\text { Quality Insecurity }\end{array}$ & $a_{2} b_{2}$ & 0.1949 & 0.0515 & 0.10850 .3103 \\
\hline & & Direct effect of Quality Insecurity on psychological distress & $\mathrm{C}_{2}$ & 0.4821 & 0.1050 & 0.27590 .6884 \\
\hline
\end{tabular}

Note: a1 a2 means "the pathway of quantitative insecurity or quality insecurity could predict self-esteem, b1 b2 means "the pathway of self-esteem could predict psychological distress, c1 c2 means "the pathway of quantitative insecurity or quality insecurity could predict psychological distress 
low self-esteem, on the other hand, exhibit limited coping resources and perceive of their professional environment as uncontrolled; these conditions subsequently increase their risk for psychological distress. Simultaneously, nurses with low self-esteem often feel incompetent and worthless-in which case, they would strive to manage the negative effects of those beliefs, perhaps in dysfunctional ways. In this way, they can become even more distressed. Inversely, nurses who have a positive sense of self-esteem are more flexible, and they can accept their strengths and weaknesses. Considering the mitigating effects of self-esteem against psychological distress, it would appear that interventions that aim to bolster self-esteem-such as training or individual sessions involving a psychological counseling platform, setting up a "peer support team," and creating a healthy organizational atmosphere-should be suggested.

This study is especially important, given that it is the first empirical attempt to reveal how self-esteem mediates between job insecurity and psychological distress among Chinese nurses. These results enrich previous findings about the explanatory mechanisms underlying the job insecurity-outcome relationship [22, 42]. The current findings indicate that modest levels of job insecurity can motivate employees to make constructive suggestions and change their current personal situationsteps that result in (and exemplify) successful coping. Conversely, high levels of job insecurity can erode an individual's competence and their ability to manage a given situation, thereby resulting in adverse mental health effects [22]. Recent research suggests that context (e.g., a supportive, cooperative work climate) can influence an individual's self-esteem, and that success or failure in various situations can result in fluctuations in an individual's self-esteem [43, 44]. Meanwhile, the current findings also support the assertion that self-esteem, as a key intermediary process, affects employees' reactions to job stressors. Considering the great importance of selfesteem against psychological distress-not to mention fluctuations in self-esteem-it appears that interventions by which to strengthen individual-level self-esteem would be of great benefit.

The current study, like all studies, has several limitations. First, due to its cross-sectional nature, we were unable to ascertain causal relationships among self-esteem, job insecurity, and psychological distress. Second, all data were collected using self-reported questionnaires, a process that incurs unavoidable reporting bias. Third, the participants were recruited from a tertiary hospital, and the sample size was small; these factors limit the generalizability of the results and weaken the statistical power. Future empirical longitudinal studies across hospitals of different classification will be required to establish causality and distinction among the variables.

\section{Conclusions}

In summary, $83.8 \%$ of the nurses participating in this study reported experiencing psychological distress. The two dimensions of job insecurity positively correlated with psychological distress, whereas self-esteem negatively correlated with psychological distress; mediation analysis showed that self-esteem was a partial mediator between the two dimensions of job insecurity and psychological distress. These findings call on health managers and researchers to take measures to strengthen self-esteem in the fight against psychological distressmeasures that can take the form of various training and/ or psychological well-being programs.

\section{Acknowledgements}

We would like to thank all the participants of this study for their involvement. We also would like to thank Editage (www.editage.cn) for English language editing.

\section{Authors' contributions}

LY \& YCY were involved in investigation, data curation and writing original draft. ZGY participated in the design of the study and produced the formal analysis, writing-review editing. All authors (LY, YCY and ZGY) have read and approved the manuscript.

\section{Funding}

The study obtained no funding.

\section{Availability of data and materials}

The datasets generated and analyzed for the current study are not publicly available due to IRB agreements but are available from the corresponding author on reasonable request.

\section{Declarations}

Ethics approval and consent to participate

The study all procedures in this study were approved by the ethics committee of Shandong Mental Health Center (2018R23) and were conducted in accordance with the ethical standards of the 1964 Helsinki declaration. All participants were informed of the purposes and procedures of the study and signed the written informed consent before the conduct of the study. During the whole study process, the privacy and anonymity of participants would be fully protected since no identifying information such as their names, addresses on any of the participants were collected. Data were summarized and reported only in the aggregate. Written permission was taken from the author of Job Insecurity Scale, Rosenberg Self-Esteem Scale (RSES) and Kessler-10 Rating Scale, respectively.

Consent for publication

Not applicable.

\section{Competing interests}

Authors declare no conflict of interest.

\section{Author details}

${ }^{1}$ Liaocheng People's Hospital, Liaocheng, China. ${ }^{2}$ Shandong Mental Health Center, 49Wenhua East Road, 250012 Jinan, P.R. China.

Received: 8 February 2021 Accepted: 27 July 2021

Published online: 10 August 2021

\section{References}

1. Kunie K, Kawakami N, Shimazu A, Yonekura Y, Miyamoto Y. The relationship between work engagement and psychological distress of hospital nurses and the perceived communication behaviors of their nurse managers: A cross-sectional survey. Int J Nurs Stud. 2017;71:115-24. 
2. Molina-Praena, Jesús, Ramirez-Baena, L., Gómez-Urquiza, José, Cañadas, Gustavo, Emilia, D. L. F., et al. Levels of burnout and risk factors in medical area nurses: a meta-analytic study. Int J Environ Res Public Health. 2018; 15(12).

3. Wang L, Wang Z, Ma Q, Fang G, Yang J. The development and reform of public health in china from 1949 to 2019. Globalization and Health. 2019; 15(1).

4. Li H, Cheng B, Zhu, XP. Quantification of burnout in emergency nurses: A systematic review and meta-analysis. Int Emerg Nurs. 2018;39:46-54.

5. Egede LE, Dismuke CE. Serious psychological distress and diabetes: A review of the literature. Curr Psychiatry Rep. 2012;14(1):15-22.

6. Prapanjaroensin A, Patrician PA, Vance DE. Conservation of resources theory in nurse burnout and patient safety. J Adv Nurs. 2017;73(11):2558-65.

7. Lambert VA, Lambert CE, Petrini M, Li X M, Zhang YJ. Predictors of physical and mental health in hospital nurses within the People's Republic of China. Int Nurs Rev. 2007:54(1):85-91.

8. Tao W, Zeng Z, Dang H, Lu B, Chuong L, Yue D, Wen J, Zhao R, Li W, Kominski GF. Towards universal health coverage: lessons from 10 years of healthcare reform in China. BMJ Glob Health. 2020;19;5(3):e002086.

9. Chen Z. Launch of the health-care reform plan in China. Lancet. 2009;373: 1322-132.

10. Wang JL, Okoli Chizimuzo TC, He HJ, Feng F, Li JW, Zhuang LL, Lin M. Factors associated with compassion satisfaction, burnout, and secondary traumatic stress among Chinese nurses in tertiary hospitals: A crosssectional study., Int J Nurs Stud. 2019;102:103472.

11. Landsbergis PA, Grzywacz JG, LaMontagne AD. Work organization, job insecurity, and occupational health disparities. Am J Ind Med. 2014;57(5): 495-515.

12. Hellgren J, Sverke M, Isaksson K. A two-dimensional approach to job insecurity: Consequences for employee attitudes and well-being. Eur J Work Organ Psychol. 1999:8(2):179-95.

13. Hans DW. Job insecurity: review of the international literature on definitions, prevalence, antecedents and consequences. SA Ind Industrial Psychol. 2005;31(4).

14. Mauno S, De CN, Tolvanen A, Kinnunen U, Mäkikangas A. Occupational well-being as a mediator between job insecurity and turnover intention: Findings at the individual and work department levels. Eur J Work Organ Psychol. 2004;23(3):381-93.

15. De Beer LT, Rothmann Jr S, Pienaar J. Job insecurity, career opportunities, discrimination and turnover intention in post-apartheid South Africa: examples of informative hypothesis testing. Int J Human Resour Manag. 2016;27(4):427-39.

16. Butterworth P, Leach LS, McManus S, Stansfeld SA. Common mental disorders, unemployment and psychosocial job quality: is a poor job better than no job at all?. Psychol Med. 2013;43(8):1763-72.

17. Shin Y, Hur WM, Moon TW, Lee S. A motivational perspective on job insecurity: relationships between job insecurity, intrinsic motivation, and performance and behavioral outcomes. Int J Environ Res Public Health. 2009;16(10):1812.

18. Ozyaman BF, Yücel D, Alp E, Yildiz A, Hans DW. Effects of perceived job insecurity on perceived anxiety and depression in nurses. Ind Health. 2008; 46(6):613-9.

19. Juliann S, Mohammed T, Redaallah A, Homaidan AT, Abdulrahman A-M, et al. Job insecurity, fear of litigation, and mental health among expatriate nurses. Arch Environ Occup Health. 2020;75(3):144-51.

20. Mann MM, Hosman CM, Schaalma HP, De Vries NK. Self-esteem in a broadspectrum approach for mental health promotion. Health Educ Res. 2004; 19(4):357-72.

21. Yang X, Lau JT, Wang Z, Ma YL, Lau MC. The mediation roles of discrepancy stress and self-esteem between masculine role discrepancy and mental health problems. J Affect Disord. 2008;235:513-20.

22. Lee JS, Joo EJ, Choi KS. Perceived stress and self-esteem mediate the effects of work-related stress on depression. Stress Health. 2013;29(1):75-81.

23. Feng DJ, Su S, Wang L, Liu F. The protective role of self-esteem, perceived social support and job satisfaction against psychological distress among Chinese nurses. J Nurs Manag. 2018;26;366-72.

24. Liu Y, Wang Z, Zhou C, Li T. Affect and self-esteem as mediators between trait resilience and psychological adjustment. Pers Individ Differences. 2014; 66:92-7.

25. Sung C, Muller VR, Ditchman N, Phillips B, Chan F. Positive coping, selfefficacy, and self-esteem as mediators between seizure severity and life satisfaction in epilepsy. Rehabil Res Policy Educ. 2013;27(3):154.
26. Servidio R, Gentile A, Boca S. The mediational role of coping strategies in the relationship between self-esteem and risk of internet addiction. Europe's J Psychol. 2018;14(1):176.

27. Wang Z, Liu H, Yu H, Wu Y, Chang S, Wang L. Associations between occupational stress, burnout and well-being among manufacturing workers: mediating roles of psychological capital and self-esteem. BMC Psychiatry. 2017;17(1):364.

28. Li QF, Chi PL, Hall Brian J, Wu QL, Du HF. Job stress and depressive symptoms among migrant workers in Macau: A moderated mediation model of self-esteem and perceived social support. Psych J. 2019:8:307-17.

29. Elizabeth JD, Kim Heejung K, Herndon Cynthia H. Social support and selfesteem as mediators between stress and antepartum depressive symptoms in rural pregnant women. Res Nurs Health. 2014;37:241-52.

30. Vispoel WP, Boo J, Bleiler T. Computerized and paper-and-pencil versions of the Rosenberg Self-Esteem Scale: A comparison of psychometric features and respondent preferences. Educ Psychol Meas. 2001;61(3):461-74.

31. Zheng $\mathrm{CH}$, Huang $X \mathrm{H}$, Yang ML, Li HP, Zeng LH. Study on the relationships between nursing professional values and self-esteem,personal development competitiveness[J].Chin J Nurs. 2009;44(6):485-7.

32. Zhang J, Guo F, Chen ZY, He HW, Long Y, Li Q. Relationship between social support, resilience, self-esteem and post-traumatic stress disorder in intensive care unit nurses [J].Natl Med J China. 2020;100(01):32-6.

33. Kessler RC, Barker PR, Colpe LJ, Epstein JF, Gfroerer JC, et al. Screening for serious mental illness in the general population. Arch Gen Psychiatry. 2003; 60(2):184-9.

34. Tian X, Gao Q, Li G, Zou G, Liu C, Kong L, Li P. Resilience is associated with low psychological distress in renal transplant recipients. Gen Hosp Psychiatry. 2016;39:86-90.

35. Welsh J, Korda RJ, Banks E, Strazdins L, Joshy G, Butterworth P. Identifying long-term psychological distress from single measures: evidence from a nationally representative longitudinal survey of the Australian population. BMC Med Res Methodol. 2020;20(1):55.

36. Zou G, Shen X, Tian X, Liu C, Li G, Kong L, Li P. Correlates of psychological distress, burnout, and resilience among Chinese female nurses. Ind Health 2016;54(5):389-95.

37. Wang H, Wang S, Liu D. An Empirical Study on the Relationship between Job Insecurity and Work Engagement Towards Nurses in Different Forms in Tertiary Hospitals. Chinese Hosp Manag. 2016,36(3):74-6.

38. Baron RM, Kenny DA. The moderator-mediator variable distinction in social psychological research: Conceptual, strategic, and statistical considerations. J Pers Soc Psychol. 1986;51(6):1173.

39. Preacher KJ, Hayes AF. SPSS and SAS procedures for estimating indirect effects in simple mediation models. Behav Res Methods Instruments Computers. 2004;36(4):717-31.

40. Yuko K, Hideki H, Hisashi E. Gender differences in the effects of job insecurity on psychological distress in Japanese workers: a population-based panel study. Int Arch Occup Environ Health. 2018;91:991-9.

41. Wang HJ, Lu CQ, Siu OL. Job insecurity and job performance: The moderating role of organizational justice and the mediating role of work engagement. J Appl Psychol. 2015;100(4):1249.

42. Auerbach RP, Abela JZ. Ho MHR, Mcwhinnie CM, Czajkowska Z. A prospective examination of depressive symptomology: understanding the relationship between negative events, self-esteem, and neuroticism. J Soc Clin Psychol. 2010;29(4):438-61.

43. Kernis MH. Measuring self-esteem in context: the importance of stability of self-esteem in psychological functioning. 2005;3(6):1569-605.

44. Franck E, Raedt RD, Houwer JD. Implicit but not explicit self-esteem predicts future depressive symptomatology. Behav Res Ther. 2007:45(10):2448-55.

\section{Publisher's Note}

Springer Nature remains neutral with regard to jurisdictional claims in published maps and institutional affiliations. 